\title{
Works of the Marine Hydrophysical Institute of the Russian Academy of Sciences in the field of remote sensing of seas and oceans (to the $90^{\text {th }}$ anniversary of the institute)
}

\author{
Pavel P. Yermolov ${ }^{*}$
}

Sevastopol State University, 33, Universitetskaya Str., Sevastopol, 299053, Russian Federation

\begin{abstract}
The report considers a brief history and the most important results of the Department of Remote Methods of Research of the Marine Hydrophysical Institute of the Russian Academy of Sciences. Information is given about the founder of the institute, Academician V. V. Shuleikin (1895-1979), the director of the institute in 1974-1985 and the founder of the direction "satellite hydrophysics", Academician B. A. Nelepo (19322007). For the first time, the information about one of the founders of the radiophysical methods of remote sensing of the ocean, a representative of the Kharkov scientific school V. V. Pustovoytenko (1946-2015), who worked in Sevastopol for the last forty years of his life and devoted scientific work to the development of satellite hydrophysics, was first introduced into scientific circulation. The general characteristic of the Institute's work in the field of satellite oceanology is given, and the most significant results associated with the operation of the Kosmos- 1500 spacecraft, as well as the specifics of the TPO-05 program and the Veyer-6 project, are considered.
\end{abstract}

\section{Introduction}

Federal Research Center "Marine Hydrophysical Institute of the Russian Academy of Sciences" (MGI) is one of the leading oceanological centers in the world. It consists of 15 research departments, the work of one of which - the Department of distance research methods - is the subject of this article. The material in this article is based on the information contained in the monograph [1] published for the $80^{\text {th }}$ anniversary of the MGI, as well as in the monograph [2] published later.

\section{A brief history of $\mathrm{MGI}$ and remote sensing}

In April 1929, on the initiative and under the leadership of Academician Vasily Vladimirovich Shuleikin (1895-1979), on the Black Sea, in Katsiveli village in the Crimea, the world's first stationary marine hydrophysical station was created, designed to carry out

\footnotetext{
${ }^{*}$ Corresponding author: p.p.yermolov@mail.ru
} 
systematic studies of processes and phenomena in the coastal zone of the sea and the atmosphere. In Moscow in 1948, the Marine Hydrophysical Institute (MGI) of the USSR Academy of Sciences was established on the basis of the Black Sea Hydrophysical Station of the USSR Academy of Sciences and the Marine Hydrophysical Laboratory (formerly a department of the Institute of Theoretical Geophysics of the USSR Academy of Sciences). Its director and organizer was V.V. Shuleykin, the founder of a new domestic direction in geophysics - sea physics. His name was associated with important scientific achievements of the Marine Hydrophysical Institute, such as studies of thermal phenomena in the ocean, the thermal interaction between the ocean, atmosphere and continents, as well as the influence of the ocean on climate and weather. V.V. Shuleikin and his students carried out a large number of experimental and theoretical studies in such scientific fields as hydrooptics, hydroacoustic, electromagnetic phenomena in the sea, molecular physics and biophysics of the marine environment. The results of these and other studies are summarized by the scientist in the monograph "Physics of the Sea", awarded in 1942 by the Stalin Prize. In August 1961, the Marine Hydrophysical Institute was transferred to the Academy of Sciences of the Ukrainian SSR, and in 1963 it was relocated to Sevastopol.

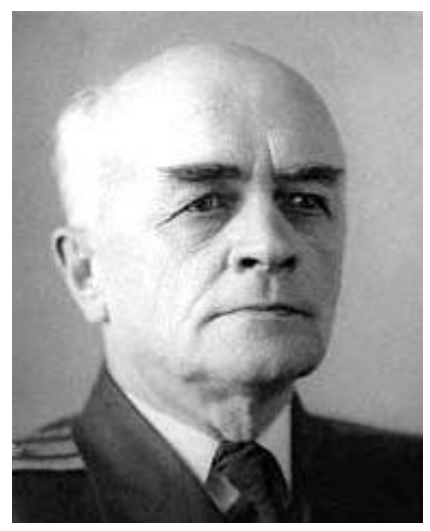

Fig. 1. Academician V. V. Shuleikin (1895-1979).

The development of satellite hydrophysics at MGI is connected with the name of Academician Boris Alekseyevich Nelepo (1932-2007), who in 1974-1985 led the institute. In these years, in cooperation with the Yuzhnoye Design Bureau (Dnepropetrovsk) and other organizations of the country under the leadership of B. A. Nelepo, the first large-scale long-term experiments on satellite hydrophysics using oceanographic satellites were carried out at the MGI. These studies became the basis of the creation of B.A. For a cycle of research in the field of satellite hydrophysics in 1989, MHI employees B. A. Nelepo and $\mathrm{Yu}$. V. Terekhin were awarded the USSR State Prize as part of the team of authors.

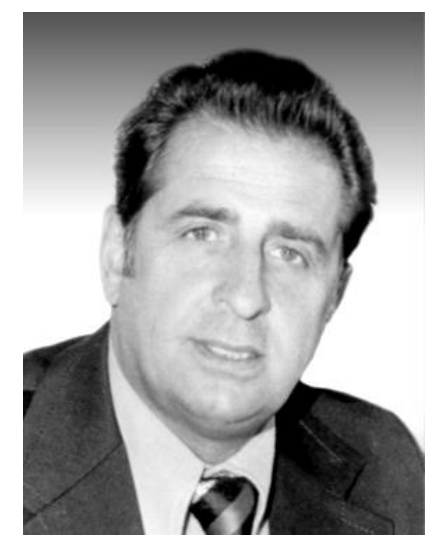

Fig. 2. Academician B. A. Nelepo (1832-2007). 
A large role in the work on remote sensing at the MHI belongs to Vladimir Vladimirovich Pustovoytenko (1946-2015). The representative of the Kharkov scientific school, V. V. Pustovoytenko was one of the founders of radiophysical methods of remote sensing of the ocean. The last forty years of his life he worked in Sevastopol, devoting his scientific activity to the development of satellite hydrophysics. He is well known as one of the leading developers of radar sensing systems for marine waters for domestic oceanographic spacecraft of the Cosmos-Ocean series, the author of several monographs, including [2]. The contribution of V. V. Pustovoytenko to the creation and development of satellite tools and methods for remote sensing of marine water areas in 1989 was awarded the USSR medal "For Labor Distinction", in 1999 - the Certificate of Merit of the Commission on World Ocean Problems of the NAS of Ukraine. In 1992-2015. V. V. Pustovoytenko is a member of the Program Committee of CriMiCo in the topic "Radio astronomy, remote sensing and radio wave propagation".

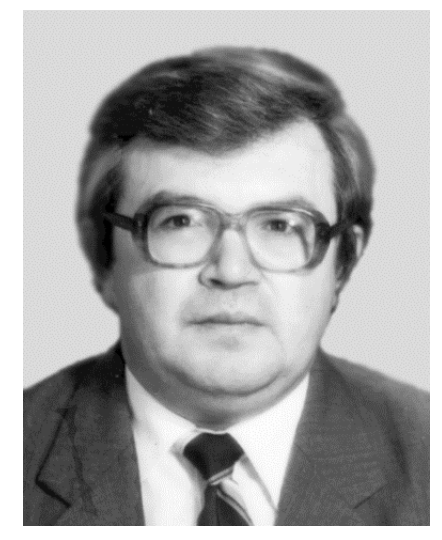

Fig. 3. V. V. Pustovoytenko (1946-2015).

\section{General characteristics of the work of the Marine Hydrophysical Institute in the field of satellite oceanology}

By the end of the 60's - beginning of the 70's world science has developed an understanding of the need for the development and widespread use of new technologies in the research of the World Ocean, based on the results obtained by remote sensing of the ocean, and allowing to obtain qualitatively new information about the processes under study, including inaccessible areas of the World Ocean. At the same time, it was a combination of new technologies with traditional ones based on the results of contact measurements. By this time, world science had studied the basic laws of the formation of information signals by an agitated sea surface in a wide spectrum of electromagnetic waves, including in the visible, infrared (IR) and ultra-short-wave (VHF) ranges. In the USSR (Cosmos-243 space vehicle, 1968) and in the USA (Skylab orbital station, 1973), experiments were carried out on the use of radiophysical means in marine research. Operational space observational meteorological systems were created - Meteor in the USSR (accepted for regular operation in 1969) and NOAA in the USA. The issues of creating a space observational system for oceanographic purposes in these years have been systematically discussed both among academic science and among the creators of space technology. Naturally, the Marine Hydrophysical Institute - a leader in the field of marine research and scientific marine instrumentation - could not stay away from the processes taking place in world science.

The association of specialists in the field of marine physics, mathematics, mathematical and physical modelling of marine systems, designers and developers of electronic 
equipment, specialists in other areas of science and technology distinguished it from other academic institutes and made it possible to carry out not only scientific and methodological developments, but also participate directly in the creation of satellite information-measuring systems. By the end of the 70's, the institute confidently took a leading position in the USSR in the field of satellite oceanology and became an equal participant in international programs in the field of remote sensing of the ocean.

At this time, the chief designer of the NGO named after S. A. Lavochkin, corresponding member of the Academy of Sciences of the USSR V. M. Kovtunenko attracted the Marine Hydrophysical Institute to work on the creation of the Ocean-E experimental space-based observing system for oceanographic applications. Under the direction of the chief designer B. Ye. Khmyrov, the Cosmos-1500 radar spacecraft (SC) and experimental models of the Ocean series spacecraft were created. Under the leadership of the chief designer of the academician of the National Academy of Sciences of Ukraine S. N. Konyukhov, the experimental spacecraft of the Ocean series have been refined to operational status, the development of the spacecraft of the Ocean-O operational oceanographic space observation system has begun.

In the process of formation and development at the institute of work in the field of satellite oceanology (hydrophysics), several stages can be noted that differ in goals, objectives and the composition of the work and performers.

At the initial stages, from the positions of system analysis and mathematical modelling of complex systems, the capabilities of space systems were studied, attempts were made to formulate in general terms recommendations for the optimal construction of satellite measurement systems, and information obtained from the observation of marine areas from the Cosmos-243 spacecraft was analysed (launched on September 23, 1968) and "Tiros", a search was carried out for options for sharing information obtained by contact and remote measurements, etc.

In its modern form, the scientific direction "Satellite Oceanology (hydrophysics)" was created at the second stage. At that time, the institute became the leading organization in the field of satellite oceanology and carried out a set of fundamental research and development efforts that allowed, on the one hand, to develop a methodology for constructing a domestic oceanographic space observing system, and on the other hand, to create unique remote sensing complexes marine water areas, as well as hardware and software systems for receiving and processing satellite information, to prepare qualified specialists Comrade in the field of satellite hydrophysics, etc. These years are characterized by intensive expeditionary activity, the establishment of close contacts with related research centres and specialists - during this period, leading specialists in this field from the USSR made speeches on remote sensing problems at the institute and the United States, R. Z. Sagdeev, N. A. Armand, J. Apel, and others, all-union meetings, seminars, and conferences on problems of satellite hydrophysics were held, etc.

Coordinating as the lead organization the work in the field of satellite oceanology, carried out in other research, design organizations of the Academy of Sciences of the Ukrainian SSR, the Academy of Sciences of the USSR and other departments, the institute in these years focused its efforts on the following main areas:

- the development of methodological support for the use of satellite information in modern oceanological research;

- the creation of modern satellite-based remote sensing facilities for marine areas;

- development of a methodology for the development and equipping of control and calibration ranges as elements of a space observing system;

- the creation of means for receiving and processing satellite information;

- participation in the implementation of international programs and projects in the field of remote sensing of the Earth (ERS). 
A significant result of the work of this period was the preparation and conduct of space experiments "Ocean-E" and "Ocean-O" aimed at the practical creation of elements of experimental and operational oceanographic space-based observing systems.

The Institute's specialists took a direct part in the development and manufacture of remote sensing systems for the Cosmos-1076, Cosmos-1151, Cosmos-1500, Cosmos-1602 and others spacecraft, and in the implementation of the Intercosmos CMEA program, in the collaboration of the USSR and the USA in the framework of the working group of the USSR Academy of Sciences and NASA in the area of Earth Sciences. With the involvement of aviation and naval means of satellite support, the institute carried out a number of satellite experiments, such as Intercosmos - Black Sea, Tien Shan Intercosmos-88, Atlantika-87, -89, MOZ-NATURE, MERIS - Black Sea.

The Institute's work on methodological support of works on remote sensing of the sea surface from space, on the creation of satellite-based instruments for remote sensing of sea water areas and the use of the obtained information in the field of marine sciences and technologies were exhibited at the exhibitions of achieving the national economy in Moscow and Kiev.

The current stage in the development of the scientific direction "Satellite Oceanology (hydrophysics)" is characterized by a transition to a more perfect description and analysis of processes observed on the sea surface. The predominant focus of the work carried out at this stage was the development of applied technologies for the use of satellite information in solving problems in the field of marine physics, the ecology of marine systems, the development of mineral and biological resources of the shelf, while modelling marine and atmospheric processes, etc. Much attention is paid to works aimed at further investigation of the features of the physical mechanisms of imaging of the sea surface, and in particular, its radar images.

\section{Spacecraft "Cosmos-1500"}

An essential step in the development of the Ocean-E experiment was the creation of the Cosmos-1500 radar oceanographic spacecraft. Its launch was preceded by the flight design tests of the Sigma-A radar system on board the Cosmos-1151 spacecraft, which became the prototype of a more advanced side-scan radar station.

The experience gained in creating the elements of on-board information-measuring complexes of oceanographic spacecraft, the positive results of flight design tests of the instruments included in their composition (designed and manufactured, by the way, by academic organizations) allowed us to proceed with the creation of a new oceanographic spacecraft equipped with a radiophysical remote sensing complex. Which included:

- sideways-looking radar operating in the centimeter range of radio waves;

- a scanning radiometer operating in the 8 - $\mathrm{mm}$ range of radio waves;

- a radio-television complex (RTVK) as part of a multi-zone scanning opticalmechanical low-resolution device (MSU-M) and a radio-transmitting complex operating in the meter and decimeter ranges of radio waves;

- microwave radiometric complex (polarimeter similar to that used on the Cosmos-1076 and Cosmos-1151 spacecrafts).

The Cosmos-1500 spacecraft launched on September 28, 1983 was the first of a series of domestic oceanographic spacecraft. This spacecraft was, in fact, the ancestor of the wellknown series of satellites Ocean- 01 .

The main tasks of launching the Cosmos-1500 spacecraft were:

- development of remote sensing methods for the oceans and the Earth's surface in the interests of various sectors of the economy and science; 
- conducting operational surveys of ice coverings in the Arctic and Antarctica to ensure navigation in the freezing regions of the oceans;

- development of new types of information-measuring equipment.

The key element of the SC scientific equipment complex was the sideways-looking radar and the scanning radiometer RM-08. Both devices were focused on obtaining images of the underlying surface. The use of the RTVK complex of the radio-television complex on board the spacecraft made it possible to directly receive radar images by a wide range of consumers who had at their disposal autonomous points for receiving satellite meteorological information (APPI). For this, both devices were coupled through their information flows with the bandwidth of the RTVK radio channels - the images were transmitted in the international standard APT (Automatic Picture Transmission - a format for transmitting images obtained using satellite scanning systems with low resolution) and were received as at specialized reception centers and processing satellite information of the USSR State Committee for Hydrometeorology (in the range of $460 \mathrm{MHz}$ ) and in the network of autonomous points for receiving meteorological information (in the range of $137 \mathrm{MHz}$ ). One of these points was deployed at the Moscow State Academy of Sciences, Ukrainian SSR.

The complexity of the problems solved during the creation of the sideways-looking radar and RM-08 radars required the combined efforts of many research and production organizations of the Academy of Sciences and the Ministry of Higher Education of Ukraine, the USSR Academy of Sciences and industrial organizations of other ministries and departments of Ukraine and the USSR.

The results obtained during the experimental operation of the sideways-looking radar on the Cosmos-1500 spacecraft were so impressive that in a short time it was organized its industrial production at one of the serial radio engineering plants in Ukraine.

To obtain images of the sea surface in the visible range on the spacecraft, the RTVK complex was used, which was commercially available and used as a standard remote sensing instrument on meteorological spacecraft of the Meteor series. The Cosmos-1500 spacecraft was the first to create a "combined frame" formation mode, when images of approximately the same surface strip were obtained on one photobase using three different instruments - sideways-looking radar, RM-08 and one of the multi-zone scanning channels optical-mechanical device of small resolution (MSU-M).

The installation of the Radon microwave radiometric complex aboard the spacecraft made it possible to continue working on the development of principles and methods for determining the temperature fields of the World Ocean, including its energy-active zones.

By the time the Cosmos-1500 spacecraft was launched on the Northern Sea Route, there was a crisis: in the Long Strait, a caravan of vessels carrying cargo needed in the Far North was "jammed" in the ice. The ship "Nina Sagaidak" was lost, a real threat arose of the complete loss of the caravan. The sideways-looking radar Cosmos-1500 became the only device that allowed to regularly review the strait and the adjacent areas of the Arctic Ocean. The study of radar information allowed the headquarters of the rescue operation to navigate the real ice situation in the region and make the decisions necessary to save the caravan.

A year later, a similar situation repeated in the seas of Antarctica, where the expeditionary ship "Mikhail Somov" turned out to be frozen into ice. The headquarters of the rescue operation no longer doubted the need for the use of radar information. The Cosmos-1500 spacecraft (by this time, the set of scientific equipment installed on its board, including the radar station and information transmission channels, had long developed its guarantee resource) and this time brilliantly coped with the role of a "space pilot".

In 1987, the radar data on the real ice situation in the Arctic were used to conduct the Siberia nuclear-powered icebreaker to the North Pole and to deploy the North Pole-29 polar station. 
Thus, the work performed using the sideways-looking radar on the spacecraft Cosmos1500, Cosmos-1602 (launched on 05/28/1984), Cosmos-1766 (launched on 07/29/1986), and Cosmos- 1869 (launched on July 16, 1987) and the Ocean-01 spacecraft (the first of which was launched on July 5, 1988), allowed us to obtain extensive factual material confirming the correctness of the basic ideas and ideas used in the design of the sidewayslooking radar. It was shown that the sideways-looking radar, with a spatial resolution of $1.5-2 \mathrm{~km}$, can be used both for determining the parameters of ice fields in the freezing regions of the World Ocean and for ensuring navigation safety, and for observing on the sea surface the manifestations of many processes, in particular, those occurring in thicker than water and in the driving layer of the atmosphere. Using this system, you can:

- observe the structure of the wind field above the sea surface;

- detect areas of intense disturbance;

- detect the presence in water of various surfactants (oil films, etc.);

- detect surface manifestations of intense internal waves;

- identify areas of intense temperature fronts on the sea surface, etc.

\section{The TPO-05 program}

In 1986, an interdepartmental working group created by order of Academician of the Academy of Sciences of the USSR G. I. Marchuk developed a program for studying the energy-active zones of the World Ocean (TPO-05 program), one of the goals of which was to create a complex of satellite measuring equipment for microwave, infrared, and visible ranges and the corresponding methodological and software-mathematical support, allowing to determine the surface temperature of the ocean with a standard error of not more than $0.5^{\circ} \mathrm{C}$. The program provided for carrying out broad theoretical research related to the improvement of physical models, scientific and methodological experiments aimed at developing sounding methods taking into account the multifactorial nature of the data obtained and the creation of an appropriate measuring complex.

The results of the Ocean-E experiment as a whole confirmed the efficiency of the created methods for determining the parameters of the atmosphere and sea surface based on the use of satellite information and the high potential capabilities of the used remote sensing complexes. At the same time, in the course of the work, certain shortcomings of the remote sensing means used in the experiment were identified, in particular, the spectral composition of the channels of microwave radiometric complexes that was not optimal for determining the parameters of the sea surface, the need to use "split" channels operating in the infrared range, insufficient frequency satellite surveys of the North Atlantic both in space and in time, etc. To eliminate these and other shortcomings was supposed to be carried out during the work on the Ocean-O program.

\section{6 "Veyer-6" project}

The Veyer- 6 project carried out as part of the Ocean-O program was, in fact, the first stage of work to implement the TPO-05 task (program). The project provided for the development of a set of issues related to both measurement methods and the creation of a direct microwave radiometric measuring complex. At the same time, the Veyer-6 system for parallel viewing of the underlying surface was provided with remote sensing scanning equipment operating in the microwave and infrared ranges, with the maximum use of subsatellite calibration information.

It was assumed that the main components of the equipment complex of the new oceanographic spacecraft will be: 
- multi-beam parallel viewing system "Veyer-6" (wavelength $6 \mathrm{~cm}$ );

- Veyer-225 multi-beam parallel viewing system (wavelength $2.25 \mathrm{~cm}$ );

- scanning system "Delta" (wavelengths $0.8 ; 1.35 ; 2.25$ and $4.5 \mathrm{~cm}$ );

- single beam scatterometer with circular beam scanning (wavelength 4-5 cm).

The Veyer-6 project took into account, to the maximum extent, the conclusions and recommendations formulated by the results of the Ocean-E experiment. The hardware complex included characteristics that made it possible to obtain estimates of the ocean surface temperature (TPO) fields with a standard error of no more than $1.0 \mathrm{~K}$ and a drive wind speed with a standard error of $3 \mathrm{~m} / \mathrm{s}$, which made it possible to use the obtained information both in hydrodynamic models and solving problems of operational oceanography, ecology, etc.

The development of the "Veyer-6" complex was carried out by specialists from the Moscow State Academy of Sciences, USSR Special Design Bureau, Moscow State Academy of Sciences, Kazan Aviation Institute of the USSR Ministry of Higher Education, and the Sevastopol Instrument-Making Institute of the Ministry of Higher Education of Ukraine. The development consultants were the IRE of the USSR Academy of Sciences and experimental design bureau at MPEI. The created microwave radiometric complex was a transition between track and scanning radiometers. While maintaining the sensitivity of the trace radiometer, it ensured, by synchronously observing the surface with six rays, the possibility of observing the ocean surface in a wide band with almost continuous overlap in the North Atlantic. The use of the complex in studying the features of the ocean surface temperature fields, on the one hand, made it possible to reduce the time of information collection and increase the frequency of its updating, and, on the other hand, made it possible to control the variability of the structure of temperature fields, which is especially important when monitoring energy-active zones of the ocean.

Another, equally important area of work within the framework of the Veyer- 6 project carried out at the Moscow State Institute was the development of a software package for preliminary processing of information obtained using the Delta scanning radiometric complex. As part of this area, the Institute's specialists developed a methodology for sharing data from radiometric systems operating in the microwave and infrared ranges for mutual field calibration. The data of microwave radiometric systems were calibrated using infrared scanners from NOAA meteorological satellites, ship and other reference data. The results of this development anticipated the ideology of TVET restoration developed in the GODAE project and were used in Russian remote sensing programs.

The Veyer-6 project, in fact, was, due to various circumstances, the last of the projects carried out at the institute in the field of satellite scientific instrumentation.

The methodical development of the project was carried out under the general guidance of Yu. V. Terekhin V. S. Suetin, A. M. Ignatov, Yu. B. Ratner, V. V. Pustovoytenko and others. Technical design was carried out in the Special Design Bureau of the Moscow State Institute of Physics, where the general management of the work was assigned to M. M. Kolomoytsev, V. G. Sivkov, P. P. Yermolov, engineers P. V. Artyukhov, V. I. Vedishchev, L. A. Shalin, P. A. Yushkina, V. M. Lyulko and others took part in the design work [1]. The manufacture of the device was entrusted to pilot production. It was assumed that the development within the framework of the Veyer- 6 project of the methods of microminiaturization of electronic equipment made it possible to further apply them in the design and manufacture of immersed and towed measuring systems.

\section{Conclusion}

The report shows the contribution of the Department of Remote Sensing Research of the Marine Hydrophysical Institute of the Russian Academy of Sciences, celebrating its $90^{\text {th }}$ 
anniversary, to the development of remote sensing technologies for seas and oceans. The material of the report will help create a holistic picture of the history of research conducted in Sevastopol in the field of radio technology.

\section{References}

1. V.N. Yeremeyev, ed. Razvitiye morskikh nauk i tekhnologiy v Morskom gidrofizicheskom institute za 75 let [The development of marine sciences and technologies at the Marine Hydrophysical Institute for 75 years] (MGI NAN Ukrainy, Sevastopol, 2004)

2. V.V. Pustovoytenko and A.S. Zapevalov, Operational Oceanography: Satellite altimetry - the current status, prospects and problems (Sevastopol, 2012) 